\title{
EDUCAÇÃO FÍSICA, FORMAÇÃO CONTINUADA E PAULO FREIRE: reflexões sobre uma proposta pedagógica remota
}

\author{
Danielle Müller de Andrade \\ Fabiana Celente Montiel \\ Márcia Rejane Vieira Guimarães
}

Resumo

Este artigo, fruto do desenvolvimento de uma atividade pedagógica não presencial denominada Estudos Avançados em Educação, do Curso de Especialização em Esporte Escolar do Instituto Federal de Educação Ciência e Tecnologia Sul-rio-grandense - campus Pelotas, teve como objetivo compreender como a discussão feita no decorrer das atividades desenvolvidas tocou e mobilizou os/as estudantes, individual e coletivamente, bem como se os/as provocou à reflexão acerca do seu papel social como educador/a e como cidadão/ã. O corpus de análise, constituído de memórias reflexivas escritas pelos/as estudantes como tarefa final, foi analisado por meio da metodologia de análise textual discursiva. Os resultados apontam a contribuição da proposta pedagógica para a formação continuada de professores/as, bem como para a reflexão acerca do papel social da Educação Física e de sua contribuição para a formação de sujeitos críticos, participativos e compromissados com a transformação social e com a promoção de uma educação pública e de qualidade para todos/as.

Palavras-chave: formação docente; atividades remotas; educação física.

\section{PHYSICAL EDUCATION, CONTINUING EDUCATION AND PAULO} FREIRE: reflections on a remote pedagogical proposal

\begin{abstract}
This paper has stemmed from an online pedagogical activity called Advanced Studies in Education carried out in the Specialization Course in School Sports of the Federal Sul-rio-grandense Institute of Education, Science and Technology - Pelotas campus. The aim is to understand how the discussion held along the activities performed has touched and affected the students, both individually and collectively, and ascertain whether it has led them to reflect on their social role as educators and citizens. The corpus of analysis, consisting of reflective memories written by the students as a final assignment, was analyzed by means of the discursive textual analysis. The results have pointed out the contribution of the pedagogical proposal to teacher continuing education and the reflection on both the social role of Physical Education and its contribution to produce critic, participatory subjects committed to social change and promotion of public, high quality education for all.
\end{abstract}

Keywords: teacher education; remote activities; physical education. 


\section{EDUCACIÓN FÍSICA, FORMACIÓN CONTINUA Y PAULO FREIRE:} reflexiones sobre una propuesta pedagógica a distancia

\section{Resumen}

Este artículo, fruto del desarrollo de una actividad pedagógica no presencial denominada Estudios Avanzados en Educación, del Curso de Especialización en Deporte Escolar del Instituto Federal de Educación, Ciencia y Tecnología Sul-rio-grandense - campus Pelotas, tuvo como objetivo comprender cómo la discusión realizada durante las actividades desarrolladas tocó y movilizó los/as estudiantes, individual y colectivamente, así como si se los/as provocó a la reflexión sobre su papel social como educadores/as y como ciudadanos/as. El corpus de análisis, compuesto por memorias reflexivas escritas por los/as estudiantes como tarea final, fue analizado mediante la metodología del análisis textual discursivo. Los resultados apuntan a la contribución de la propuesta pedagógica para la formación continua de profesores/as para la reflexión sobre el papel social de la Educación Física y de su contribución para la formación de sujetos críticos, participativos y comprometidos con la transformación social y con la promoción de una educación pública y de calidad para todos/as.

Palabras clave: formación docente; actividades remotas; educación física.

\section{INTRODUÇÃO}

O ano de 2020 surpreendeu a todos e todas com a pandemia de Covid-191 no mundo inteiro e, especialmente no Brasil, escancarou a desigualdade social, acentuou a necessidade imediata de repensarmos a Educação e a forma como os processos de ensino e de aprendizagem vêm sendo desenvolvidos no âmbito das Instituições de Ensino (IE), nas diferentes redes e níveis escolares.

As atividades remotas configuraram-se como alternativa encontrada mundialmente para dar continuidade aos processos educacionais. Esses foram afetados em decorrência da necessidade de distanciamento sanitário e, especialmente no Brasil, houve uma perda da qualidade da Educação, visto que muitos/as estudantes e professores/as encontravam-se e, ainda se encontram, em situação delicada, seja por aspectos de ordem social, econômica e/ou emocional.

Com base no cenário do ano de 2020, depois de alguns meses de muitas discussões e resistência, o Instituto Federal de Educação, Ciência e Tecnologia Sul-rio-grandense (IFSul) elaborou e teve aprovação pelo Conselho Superior (CONSUP) 2, em agosto de 2020, suas diretrizes para o desenvolvimento de Atividades Pedagógicas não Presenciais (APNP), adotadas em razão da pandemia de Covid-19 (IFSUL, 2020). A partir dessas diretrizes surgiu a possibilidade de dar continuidade ao calendário letivo, até então suspenso, ou construir um calendário extraordinário. Os diferentes campi iniciaram o planejamento e proposições de suas APNP, o campus Pelotas, após debate com a sua comunidade, optou pela oferta de um calendário extraordinário.

A proposição de um calendário extraordinário tinha como intuito a manutenção dos vínculos entre estudantes e professores/as, além de proporcionar uma reaproximação dos estudantes do campus Pelotas aos processos educativos. Paralelamente a esse processo os/as docentes do curso de Especialização em Esporte Escolar do IFSul - campus Pelotas iniciaram suas discussões e

\footnotetext{
1 Covid-19 é uma doença causada pelo coronavírus denominado SARS-CoV-2, que desde 2019 tem levado milhares de pessoas ao óbito. (MINISTÉRIO DA SAÚDE, 2021).

2 O CONSUP, de caráter consultivo e deliberativo, é o órgão máximo do Instituto, ao qual compete as decisões para execução da política geral, em conformidade com o estabelecido pelo Estatuto, pelo Regimento Geral e regulamento próprio.
} 
encaminhamentos a respeito do que seria proposto aos/às estudantes no calendário extraordinário aprovado para ser desenvolvido em dez semanas.

O cenário educacional, as incertezas e angústias vivenciadas por nós - professoras do curso nas reuniões, capacitações, lives, assim como a observação cotidiana de como vinham ocorrendo as atividades remotas em diferentes redes, foi o que nos incentivou a propor uma APNP que tivesse como foco discutir, junto aos/às estudantes, muitos/as professores/as de outras IE, o atual cenário educacional.

Nesse sentido, o presente artigo tem como objetivo compreender como a discussão realizada no decorrer da APNP Estudos Avançados em Educação tocou e mobilizou os/as estudantes, individual e coletivamente, e se os/as provocou à reflexão de seu papel social como educador/a e como cidadão/ã.

\section{APNP Estudos Avançados em Educação}

Ao acompanhar as atividades remotas, percebemos que a forma com que as atividades educativas estavam sendo realizadas, em sua maioria, era incompatível com uma formação humanizada e transformadora, como preconizada por Freire (1996; 2011a; 2011b; 2016) e com o que entendemos ser o papel social da Educação. Tais atividades, a cada dia, davam uma maior visibilidade à enorme desigualdade social brasileira.

Entendemos ser importante refletir e resistir à reprodução de uma Educação bancária e conteudista, como foi possível perceber em muitas propostas de IE. Para tanto, quando tivemos a oportunidade de pensar e propor alguma atividade para o curso de Especialização em Esporte Escolar, decidimos que teria que ser diferente. Não podíamos fazer mais do mesmo. Queríamos compartilhar com colegas de profissão, professores/as, a maioria de Educação Física (EF), as angústias, os medos, os desejos e as possibilidades que percorriam nossos pensamentos.

Transformar tal intenção em realidade não foi uma tarefa fácil, já que somos professoras, mulheres, mãe e donas de casa. Ao mesmo tempo, uma fagulha de revolução acendeu nos nossos corpos amedrontados pelo que estávamos vivenciando, instigando-nos a elaborar e efetivar a APNP Estudos Avançados em Educação.

A APNP Estudos Avançado em Educação teve como ementa o ensino do esporte escolar nos diferentes tempos e espaços da Educação brasileira; políticas educacionais, currículo e trabalho docente; saúde do/a professor/a; exclusão e desigualdade escolar. Para o desenvolvimento da APNP e para o alcance dos objetivos traçados, foram selecionadas quatro lives de educadores/as e organizada uma roda de conversa, as quais serviram de suporte para a escrita das memórias reflexivas dos/as estudantes, assim como para as discussões realizadas nos encontros síncronos3.

As ferramentas utilizadas foram: o YouTube e quatro lives - disponibilizadas nele, o ambiente virtual de aprendizagem Moodle, artigos e textos disponíveis de forma online, o Google Jambord, a plataforma Jitsi Meet - para a realização da roda de conversa e a plataforma do Google Meet para realização dos demais encontros síncronos.

Como forma de avaliação, e compreendendo essa de forma processual, foi solicitada, a cada atividade síncrona e assíncrona, a elaboração de um breve registro escrito sobre o tema debatido, denominado de memórias reflexivas, postadas no Moodle. Também foi considerada a participação

\footnotetext{
3 Encontro síncrono é a denominação das atividades de comunicação e interação, realizadas em tempo real, através de plataformas virtuais.
} 
nos debates realizados nos encontros síncronos e foi solicitada a escrita de um texto reflexivo final, tendo como parâmetro as memórias elaboradas ao longo da APNP.

\section{CAMINHO METODOLÓGICO}

As escolhas metodológicas assumidas caracterizam o presente estudo como qualitativo, de caráter descritivo, que segundo Gil (2008) apresenta como característica a descrição de determinado fenômeno. O estudo concentrou-se nos trabalhos finais da APNP Estudos Avançados em Educação dos/as estudantes matriculados/as no curso de Especialização em Esporte Escolar, do IFSul - campus Pelotas.

O curso, que está em sua primeira turma, possui atualmente 13 estudantes com matrículas ativas, do total de 17 que ingressaram em agosto de 2019. Desse total, nove optaram por realizar a APNP ofertada durante o período de pandemia de Covid-19. Esses/as estudantes são os/as participantes do presente estudo.

Os instrumentos utilizados para a produção dos dados foram os textos reflexivos construídos pelos/as estudantes por meio do registro de memórias reflexivas realizadas no decorrer da APNP. Importa sinalizar que os/as estudantes autorizaram o uso dos seus trabalhos finais para a escrita deste artigo. Seus codinomes, neste estudo, são: Ana, Denise, Flávia, Fábio, Inácio, Joana, Marta, Pedro e Vítor.

A respeito do trabalho final os/as estudantes foram provocados/as a pensar a respeito das seguintes questões: Como a discussão proposta no decorrer da APNP te toca/tocou e mobiliza/mobilizou, individual e coletivamente? Qual o teu papel social como educador/a e como cidadão/ã? De que forma a conjuntura atual da Educação influencia as relações sociais e de trabalho? A APNP contribuiu para a transformação e/ou renovação da tua prática pedagógica? Como a discussão realizada durante a APNP pode potencializar o desenvolvimento da Educação crítica, transformadora, autônoma e participativa em especial, no âmbito da EF e do esporte escolar?

Alicerçadas no pensamento de Paulo Freire, recorremos à metodologia de Análise Textual Discursiva (ATD), proposta por Moraes e Galiazzi (2011), para analisar os dados. Essa metodologia possibilita ao/à pesquisador/a compreender o fenômeno como um todo, abrangendo diferentes discursos, construídos e reconstruídos coletivamente. De acordo com Andrade, Schmidt e Montiel (2020, p. 950): "Não existe o propósito, na ATD, de testar hipóteses, para comprová-las ou refutálas, mas compreender melhor o fenômeno da pesquisa, com base na reconstrução de conhecimentos existentes acerca desse fenômeno".

Utilizamos o programa NVivo 12, que auxiliou na organização e na sistematização das informações, bem como no percurso analítico previsto pela ATD, o qual contempla as seguintes etapas: 1) leitura e organização dos textos reflexivos no programa; 2) unitarização - buscando as unidades de significado; 3) categorização - organização das categorias; 4) interpretação e descrição dos resultados a partir das três categorias finais: pressupostos pedagógicos e metodológicos da APNP; compromisso social e o fazer pedagógico de educadores/as; formação permanente do/a educador/a. 
Os/as convidados/as ao debate e à reflexão

Buscamos nos/as autores/as que sustentam a nossa prática pedagógica subsídios para nos fortalecer e fortalecer a EF pela qual lutamos. Assim, na intenção de aprofundar o debate que empenhamo-nos a realizar, trouxemos para os nossos encontros os/as educadores/as Boaventura Santos (2020b), Gaudêncio Frigotto (2020), Celi Taffarel (2020), Valdelaine Mendes, Débora Sinoti, Jônatas Borba (2020) e Raphaell Martins (2020), para que, junto aos/às estudantes, pudéssemos aprender, sentir, discutir e vivenciar a temática dessa APNP.

A live "A Cruel Pedagogia do Vírus", proferida por Santos (2020a), apresentou o cenário mundial da Educação, incitando-nos à reflexão acerca dos processos e movimentos que têm ocorrido e que contribuem para a sua mercantilização. Santos (2020a) nos convidou a pensar a Educação no contexto das sociedades capitalistas, que têm no lucro e na exploração a sua essência - o seu objetivo maior. Reflexão disponibilizada também no seu livro "Cruel Pedagogia do Vírus", lançado durante a pandemia da Covid-19 (SANTOS, 2020b).

Valemo-nos da live de Frigotto (2020), intitulada "Educação e a extrema direita: o projeto Escola Sem Partido", para debater o contexto da Educação brasileira, a qual nos fez relembrar dos avanços educacionais promovidos pelos governos Lula e Dilma, com a criação dos Institutos Federais e nos instigou ao enfrentamento, via Educação, à lógica capitalista vigente.

No sentido de trazer o debate para o campo da EF, foi realizada uma roda de conversa chamada de "Educação Física Escolar na pandemia de Covid-19: trabalho docente, currículo e aprendizagens". Mendes, Sinoti e Borba (2020) abordaram temas imprescindíveis a quem é e está compromissado/a com a Educação pública, gratuita e de qualidade. Suas falas e provocações contribuíram para a compreensão da potencialidade que tem a EF para a formação de sujeitos críticos, autônomos e participativos, ou seja, para uma formação humana, humanizante e humanizada, a qual tenha como objetivo maior o estímulo ao exercício da cidadania.

Para problematizar e aprofundar a discussão acerca do papel social da EF, recorremos à live de Taffarel (2020), eterna resistência e enfrentamento à EF tradicional. Com a temática "Educação Física Escolar e Sociedade: abordagem crítico-superadora através do tempo", Taffarel (2020) nos convidou à reflexão, a partir da trajetória epistemológica e metodológica do campo da EF, sobre o fazer de professores/as, instigando à reflexão acerca dos objetivos da EF escolar - em especial com o esporte escolar.

Para a finalização do ciclo de debates propostos e para que pudéssemos discutir a EF escolar junto com um professor de EF da rede dos IF, recorremos a live "A trajetória da Covid-19 na Educação Física Escolar”, de Martins (2020). No dia da discussão sobre a live, o professor esteve presente na sala virtual, contribuindo para a reflexão acerca do dia-dia da sala de aula em tempos da pandemia e alertando para a necessidade de enfrentamento à precarização do trabalho docente, bem como para possíveis caminhos para efetivação de uma EF crítica e transformadora da realidade.

\section{FAGULHAS E MEMÓRIAS: O ACENDER DE UM FOGARÉU}

A partir do desenvolvimento do processo analítico realizado - e das categorias que dele emergiram - alicerçada no pensamento de Paulo Freire encontramos, nos trabalhos reflexivos finais dos/as nove estudantes que participaram da APNP Estudos Avançados em Educação, indícios de que a proposta pedagógica desenvolvida contribuiu para a formação dos/as estudantes do curso, 
futuros/as especialistas em Esporte Escolar, no sentido de mobilizá-los/as à reflexão de seu papel social como educador/a e como cidadão/ã.

A respeito da categoria "Pressupostos pedagógicos e metodológicos da APNP", os registros dos/das estudantes evidenciaram como a proposta da APNP superou, não só as nossas expectativas, professoras responsáveis, mas também as expectativas dos/as estudantes, bem como evidenciaram que a APNP se configurou como um espaço de diálogo, respeito e escuta, favorecendo o estabelecimento de relações horizontalizadas e afetuosas. Freire (1996) sinaliza para a necessidade de a aula ser um lugar de escuta atenta ao/à outro/a já que "[...] é escutando que aprendemos a falar com eles. Somente quem escuta paciente e criticamente o outro, fala com ele, mesmo que, em certas condições, precise falar a ele" (p. 113).

No mesmo sentido Andrade (2021, p. 136) sinaliza que:

[...] o diálogo, numa perspectiva freiriana, demanda disponibilidade, abertura, atenção a si e ao outro, empatia e cuidado. Estar em diálogo é se reposicionar ante o outro, abandonar certezas, dar abertura ao novo e ao diferente e tornar possível a transformação de si e do outro.

Tal escuta atenta e o fomento ao diálogo foram evidenciados por Inácio e Marta, ao se referirem às dinâmicas dos encontros realizados, como indicam os excertos a seguir:

[...] faz-se importante ressaltar que em todas essas ocasiões, nossas reflexões e contribuições foram realizadas de forma coletiva entre os colegas da disciplina e, nem sempre pesando de forma igual sobre tudo, mas sempre pensando juntos sobre a conjuntura da educação brasileira no intuito de melhorar essa realidade. (INÁCIO).

Pudemos participar ativamente e debater [...] (MARTA).

Os registros de Inácio e Marta demonstram que a APNP foi um espaço de diálogo e partilha, onde $\mathrm{o} / \mathrm{a}$ estudante não fosse reduzido/a a um/a mero/a espectador/a, mas sim, que participasse durante os encontros, ativa e criticamente. Diálogo e partilha, pressupostos freirianos que favorecem a construção coletiva de estratégias para o enfrentamento e a possível superação das adversidades. Para Freire (2011b), esses dois pressupostos requerem disponibilidade, reciprocidade e afetividade. "Ao fundar-se no amor, na humildade e na fé dos homens, o diálogo se faz uma relação horizontal, em que a confiança de um polo no outro é consequência óbvia" (FREIRE, 2011b, p. 113).

Nesse sentido, e conforme expresso por Joana quando escreveu que "[...] gostaria de agradecer pela disciplina e parabenizar as professoras por nos oportunizarem tantos momentos de interação e reflexão durante estas semanas que se passaram" (JOANA), entendemos que os objetivos da APNP foram alcançados, pois queríamos oportunizar momentos de diálogo e de reflexão coletiva sobre os diversos temas abordados em cada uma das lives e na roda de conversa. O percurso pedagógico percorrido no decorrer das dez semanas, bem como nos seis encontros síncronos realizados, possibilitou a estudantes e professoras, crescer coletivamente, ensinar e aprender, ou seja, se educar na e pela dialogicidade como sinaliza Freire:

Desta maneira, o educador já não é o que apenas educa, mas o que, enquanto educa, é educado, em diálogo com o educando que, ao ser educado, também educa. Ambos assim, se tornam sujeitos do processo em que crescem juntos e em que os "argumentos da autoridade" já não valem. (FREIRE, 2011b, p. 95-96). 
A ausência de "argumentos de autoridade", como sugere Freire (2011b), coaduna a ideia de necessidade de horizontalização na relação educador/a-educando/a. Entendemos que um reposicionamento ante ao/à outro/a torna-se imprescindível para o estabelecimento de relações horizontalizadas, portanto dialógicas, afetivas, reflexivas e transformadoras.

Tanto o estabelecimento de relações horizontalizadas como a metodologia utilizada para o desenvolvimento da APNP, na qual esteve presente o fomento à participação, reflexão e construção coletiva, foram destacados pelos/as estudantes como um diferencial à sua formação pessoal e profissional, como expressou Marta: "Acredito que a forma com que a disciplina foi conduzida, as discussões, as conversas, as lives, puderam trazer outra visão para o papel da EF na educação" (MARTA).

Ademais, as contribuições da APNP evidenciadas demonstram o quanto os/as estudantes foram instigados/as à reflexão acerca do papel social da EF e da Educação, demonstrando que o desenvolvimento da APNP mobilizou e sensibilizou os/as alunos/as a novas reflexões, bem como contribuiu para o alargamento da leitura de mundo, como preconizado por Freire (1996; 2011; 2011b). Os excertos a seguir endossam nosso argumento:

Podemos discutir temas de suma importância, que muitas vezes são deixados de lado por pensarmos que não podemos fazer mais do que está ao nosso alcance. Mas precisamos buscar o melhor, e podemos levar temas como estes para que outras pessoas também possam refletir sobre eles e tentar mudar esse panorama. (FÁBIO).

Tanto os diálogos com os colegas e professores, quanto as lives provocaram diversas mobilizações no meu ser, uma em especial: em como o capitalismo e as classes dominantes querem tirar os direitos básicos das pessoas. (MARTA).

Tendo como pressuposto pedagógico e metodológico a dialogicidade, a participação e a reflexão crítica, a APNP foi uma significativa via para a formação humana, em especial para a formação de professores/as, pois engendrou a ampliação da discussão acerca das temáticas do campo da EF escolar e da Educação, bem como mostrou-se via potencializadora para a transformação da realidade.

As discussões realizadas no decorrer da APNP estimularam a reflexão acerca do compromisso social da Educação e dos/as educadores/as, bem como dos seus fazeres pedagógicos, como sinalizado na segunda categoria de análise "Compromisso social e o fazer pedagógico de educadores/as", a qual evidenciou o quanto a APNP contribuiu para o entendimento da dimensão política da Educação indo ao encontro do pensamento de Freire (1996; 2011a 2011b), que a compreende como um ato político.

Os registros também evidenciam que a APNP estimulou o desenvolvimento da criticidade, bem como promoveu a ampliação do conhecimento, ou seja, o alargamento da leitura de mundo, como sugere Freire (2011b), potencializando ações educativas estimuladoras do enfrentamento das adversidades e da transformação da realidade, como demonstra o excerto a seguir:

Fui muito tocada pelas nossas discussões durante o decorrer de nossos encontros, pois me ajudaram a perceber o quanto precisamos falar sobre política, o quanto temos que nos armar de conhecimento e lutar todos juntos pela educação que acreditamos. (DENISE). 
As lives de Santos (2000b) e Frigotto (2000) enfatizaram a crueldade do modelo social capitalista que converge para a lógica da concentração de renda. Um sistema que se ocupa, primordialmente, com o atendimento ao mercado financeiro e que, não raras vezes, exime-se do compromisso político com saúde, educação e demais pautas sociais. No sentido do enfrentamento e possível superação ao modelo social vigente, necessitamos de uma Educação politicamente comprometida com processos civilizatórios igualitários e emancipatórios, na qual educadores/as e estudantes se "armem de conhecimento", ou nas palavras de Freire (2021) impregnem-se de "amor armado".

A APNP possibilitou a ampliação dos conhecimentos acadêmicos dos/as estudanteseducadores/as do curso de especialização, reverberando, de forma pontual, nas suas práticas pedagógicas e, por consequência nos processos educativos estabelecidos nos contextos que atuam, ou seja, na Educação, como expressou Denise:

A disciplina de Estudos Avançados contribuiu muito para a renovação da minha prática pedagógica, ao mesmo tempo em que as discussões me mostraram que eu estava no caminho certo, me mostrou que eu ainda tenho muito a melhorar. [...]. A principal contribuição foi me fazer repensar o currículo da escola que atuo tentando contemplar ainda mais a eficácia das nossas ações em relação ao ensino/aprendizado. (DENISE).

Os excertos acima revelam como a proposta pedagógica da APNP contribuiu para a reflexão acerca das práticas pedagógicas, indicando que a APNP possibilitou a efetivação de uma práxis freiriana, qual seja, ação-reflexão-ação no mundo para transformá-lo. Ademais, quando Denise revela que ainda tem muito a melhorar, ela evidencia o sentido de incompletude e inacabamento freirianos e o quanto a formação continuada contribui para a renovação dos processos educativos.

No mesmo sentido, o registro de Denise indica que a APNP se constituiu via para a reflexão acerca do currículo, de modo estrito, ampliando as possibilidades dele se tornar significativo e contextualizado, qualificando os processos de ensino e de aprendizagem. Como questiona Freire:

Por que não discutir com os alunos a realidade concreta a que se deva associar a disciplina cujo conteúdo se ensina [...] Por que não estabelecer uma "intimidade" entre os saberes curriculares fundamentais aos alunos e a experiência social que eles têm como indivíduos? (FREIRE, 2011, p. 32).

Tal reflexão oportunizada indica a sua potencialidade para a efetivação de uma EF crítica, emancipatória e transformadora da realidade, indo ao encontro do destacado na live de Taffarel (2000) e na roda de conversa (MENDES; SINOTI; BORBA, 2020) quando instigaram a reflexão acerca do processo histórico da $\mathrm{EF}$, defendendo as abordagens que rompam com a lógica higienista e tecnicista, bem como defendam a construção do conhecimento a partir de uma EF comprometida com a formação de sujeitos críticos e participativos. Incitaram também o debate sobre o momento pandêmico atual, sobre a aproximação dos conteúdos da EF com as necessidades sociais do momento, em especial, as de quem está, atualmente, à margem dos processos educativos, como indica o excerto a seguir:

Pensar em o que trabalhar, para que e de que forma foi extremamente necessário para que não caíssemos no discurso da EF meramente higienista ou tecnicista e conseguíssemos pensar em aulas que fizessem sentido em um momento de pandemia. [...] Enfim, os debates em nossa disciplina, deixaram ainda mais evidentes o quanto precisamos conhecer a realidade educacional e seus 
processos, ser críticos, políticos, lutarmos para que a educação não seja sucumbida a esse processo de privatização e para que possamos juntamente com a comunidade determinar um currículo realmente significativo. (FLÁVIA).

O registro acima indica que a APNP fomentou o planejamento e desenvolvimento de atividades pedagógicas significativas e contextualizadas, contribuindo para a reflexão acerca do currículo, estrito e ampliado. Pensar o currículo da escola sugere refletir sobre as ações e relações pedagógicas estabelecidas no ambiente educativo, em especial nesses tempos de pandemia, no qual as atividades pedagógicas têm sido realizadas de modo remoto, como destacou Vítor:

Às vezes o ensino remoto é visto como sendo tão distante do aluno e sem aprendizado acontecer da maneira como "deveria ser", vendo o ensino remoto como limitado (e é), mas que também possamos olhar para esse momento como uma tentativa do mais seguro e pensando nos outros, considerando o nosso país e suas extremas desigualdades, que precisam de cuidado com uma doença que pode ser tão mortal. (VÍTOR)

A preocupação com o momento atual tem sido pauta das práticas pedagógicas de muitos/as professores/as, como sinalizado por Vítor. Porém tais práticas pedagógicas deveriam também ocupar-se em romper com a lógica da Educação bancária presente nas atividades presenciais e, neste momento, fortemente evidenciada nas atividades remotas, como sinalizado por Vitor: "Precisamos realinhar as linhas de pensamentos do papel da escola e da EF, construindo de maneira crítica os alunos, e que não sejamos abraçados pela educação bancária".

Ademais, são emergentes o enfrentamento e a defesa ao atual ataque às ciências humanas com vistas à formação multidimensional do ser humano (FRIGOTTO, 2020). O autor destaca também a necessidade de promoção de uma Educação "por inteiro", que possibilite aos/às jovens o alargamento de seus horizontes, bem como rompa com a lógica de uma Educação alienada, precarizada e desvinculada da realidade.

Nesse sentido, encontramos no registro de Fábio e de Joana indícios de que a APNP se constituiu como estratégia pedagógica condizente com a Educação emancipatória, portanto crítica e transformadora das realidades, ao expressarem que:

Nossa missão, como professores de Educação Física, vai além de apenas
desenvolver a aptidão física dos alunos, devemos desenvolver a aptidão do
pensamento crítico, contextualizando temas da cultura corporal do movimento
com o que acontece na sociedade. (FÁBIO).

Eu acredito que esse espaço de discussão serviu não somente para nós enquanto professores, para nos instrumentalizar por si só, mas também e principalmente para que nós, na nossa prática profissional, possamos atuar com clareza de ideias, posicionamento perante nosso contexto vigente e passando adiante aos nossos alunos, não somente os conteúdos por si só, mas com e através dos conteúdos formar estes alunos de forma a perceberem seus lugares de fala, suas próprias lutas, traçarem seus próprios objetivos, formando-os plenos cidadãos críticos. (JOANA).

Tais registros exprimem a compreensão acerca do papel dos/as professores/as de EF, qual seja, extrapolar a reprodução do gesto técnico e, a partir da problematização de temáticas contextualizadas, promover uma formação humanizada, autônoma e transformadora. Para Freire: 
[...] uma das tarefas mais importantes da prática educativo-crítica é propiciar as condições em que os educandos em suas relações uns com os outros e todos com o professor ou professora ensaiam a experiência profunda de assumir-se. Assumir-se como ser social e histórico, como ser pensante, comunicante, transformador, criador, realizador de sonhos, capaz de ter raiva porque capaz de amar. (FREIRE, 1996, p. 41).

Com Martins (2000) pensamos sobre o projeto EF que estamos comprometidos/as, especialmente nesse momento de atividades remotas, no qual muitos/as estudantes vêm sendo excluídos/as dos processos educativos por não terem condições estruturais e tecnológicas. Ponderamos que se faz necessário o cuidado para não reproduzir práticas educativas alienadas e descontextualizadas, onde, por exemplo, a EF volta-se apenas para a aptidão física. Esse ponto é evidenciado por Pedro:

[...] penso que a EF seja um canal de protagonismo (talvez em paralelo com as Artes, a Dança e as Ciências Psicossociais) para uma melhor expressão de educação plural consciente e humanizada, justamente por ter o privilégio de lidar com os estímulos, conflitos, alegrias e demais manifestações do ser humano na sua essência prática, na sua corporeidade, individual e coletivamente. (PEDRO).

Taffarel (2020) sugere a constituição e efetivação de uma EF diferente da tradicional, a qual não seja repelida pela lógica do pensamento médico higienista, tampouco pela militarização da Educação e pela reprodução do esporte de alto rendimento. Embasada na Pedagogia HistóricoCrítica a autora destaca a abordagem crítico superadora como aquela que propõe a construção do conhecimento, permitindo o enfrentamento das circunstâncias históricas de opressão no sentido de transformá-las e não de se adaptar e se submeter ao que está posto.

Corroborando o pensamento de Taffarel (2020), entendemos que a APNP fomentou a superação de práticas tradicionais de $\mathrm{EF}$, bem como sua renovação, indicando para a necessidade de contextualização dos conteúdos de modo que esses possam colaborar para repensar a vida em sociedade, na intenção de sua transformação, como registraram Inácio e Fábio:

Os fatos vivenciados neste semestre contribuíram imensamente para a renovação de minhas futuras práticas docentes e, para elucidar isso, faz-se necessário contextualizar um pouco sobre as discussões, reflexões e contribuições realizadas. (INÁCIO).

Com certeza, após a disciplina, sou um professor melhor, mais humano e consciente do meu papel e das minhas responsabilidades docentes. (FÁBIO).

Nesse sentido, entendemos que a APNP engendrou processos de reflexão acerca dos desafios educacionais do ano de 2020, em especial os que implicam na vida de educadores/as. Desafios que extrapolam a necessidade de ressignificação das práticas educativas, pois os/as educadores/as tiveram que lidar com as desigualdades sociais, bem como com a falta de condições de trabalho, dentre elas a dificuldade de acesso à internet, de condições físico-estruturais e da escassa oportunidade de formação continuada. Para Martins (2020), muitos/as professores/as não tiveram sequer tempo de produzir e organizar a sistematização dos conteúdos que seriam trabalhados, o que fez com que muitos, no primeiro momento, retornassem à educação conteudista, apelando para grupos de whatsapp e vídeos do YouTube. 
Desse modo, compreendemos que a segunda categoria de análise se relaciona com a última apresentada neste estudo "Formação permanente do/a Educador/a" de modo complementar, já que ambas incitam a reflexão acerca da formação de professores/as e no exercício da docência. Freire (1996) alerta sobre a importância de a formação permanente dos/as educadores/as ser pautada a partir da reflexão das suas práticas pedagógicas, que seja uma formação em serviço. A APNP ao promover a reflexão sobre o compromisso social e o fazer pedagógico dos/as estudantes do curso de Especialização em Esporte Escolar, contribuiu para a formação permanente desses/as profissionais, em uma perspectiva freiriana.

Ao fomentar a problematização das questões elencadas por Martins (2020) a APNP auxiliou na reflexão acerca dos fatores ambientais, políticos e emocionais que implicam diretamente na saúde do/da professor/a, bem como nos processos de ensino e de aprendizagem e nos processos de exclusão e desigualdade social presentes no contexto educacional em tempos de pandemia de Covid-19. Constituindo-se assim via de incentivo ao estudo e à tomada de consciência acerca da importância de aliar teoria e prática, ou seja, do quanto a teoria é fundante de práticas pedagógicas comprometidas com a formação humana.

A tomada de consciência foi registrada por Pedro ao se referir à finalização da APNP ao escrever "eu saio com a mente inquieta, criticamente desafiada, mais consciente dos meus erros e acertos e, aberta a revisitar as discussões, as lives e os livros". O sentimento de Pedro reforça a importância da constante reflexão, assim como de estarmos abertos/as à busca de novos conhecimentos. Também reforça a ideia da necessidade da consciência do inacabamento e da possibilidade do vir a ser, como preconizado por Freire (1996). Para o autor, "[c]omo professor crítico, sou um 'aventureiro' responsável, predisposto à mudança, à aceitação do diferente.” (FREIRE, 1996, p. 55).

Para Freire (2021) ensinar exige do/a educador/a uma preparação, capacitação e formação permanente, dessa forma compreendemos os cursos de Especialização uma oportunidade de qualificação profissional. Além disso, a formação continuada possibilita ao/à educador/a, que se encontra em atividade docente, o refletir a partir de sua prática pedagógica. Como sinaliza Freire (2021, p. 56): "Sua experiência docente, se bem percebida e bem vivida, vai deixando claro que ela, a experiência docente, requer uma formação permanente do ensinante. Formação que se funda na análise crítica de sua prática".

Esse aspecto é reforçado por Joana, ao expor que: "Entendo que seja constante o processo de aprendizado de qualquer pessoa e que nós professores estamos e precisamos sempre estar atentos às coisas ao nosso redor, justamente pelo nosso papel formador". O registro de Joana evidencia o compromisso docente com sua constante formação e atualização. Formação continuada que pode ocorrer por distintas vias e que, desde o ano de 2020, em decorrência da pandemia de Covid-19, vem ocorrendo por meio de redes de colaboração, como evidenciado por Silva e Martins (2020, p. 43):

Assistimos as professoras e os professores formarem redes de colaboração para o aprendizado coletivo, partilhando experiências, experimentos, formas interativas e atrativas para o trabalho com as educandas e os educandos nas aulas de Educação Física.

O aprendizado e a construção do conhecimento tornam-se significativos quando compartilhamos experiências com nossos pares e temos a oportunidade de discutir diferentes temas. É na e pela partilha de conhecimentos e afetos que professores/as crescem e se qualificam 
juntos/as, pois é na diferença que vamos nos constituindo como sujeitos e como coletivos, como pode ser observado no excerto a seguir:

É gratificante pertencer a um espaço com indivíduos de personalidades diferentes em que as opiniões divergem, é nesse momento que passamos a entender que não existe uma verdade absoluta, e que devemos aprender a lidar com o que não faz parte da nossa vida [...]. (ANA).

Problematizar, refletir, discutir e respeitar foram os verbos que conduziram o planejamento das atividades a serem desenvolvidas no decorrer da APNP. Entendemos que eles se fizeram presentes em todos os encontros síncronos e reverberam na vida pessoal e profissional de cada estudanteprofessor/a envolvido/a, reforçando a necessidade e a importância da formação continuada como possibilidade para, via reflexão crítica, nos transformarmos enquanto educadores/as e, assim, contribuirmos para a transformação da realidade e da vida das pessoas. Freire (1996) reforça esse ponto ao destacar que:

[...] na formação permanente dos profissionais, o momento fundamental é o da reflexão crítica sobre a prática. É pensando criticamente a prática de hoje ou de ontem que se pode melhorar a próxima prática. O próprio discurso teórico, necessário à reflexão crítica, tem que ser de tal modo concreto que quase se confunda com a prática. (FREIRE, 1996, p. 43).

Ademais, a APNP colaborou para a consolidação do papel social dos/as estudantesprofessores/as participantes, possibilitando que, por meio das reflexões realizadas, olhassem para si e para suas práticas pedagógicas, reafirmando convicções ou estabelecendo novas compreensões, o que pode ser observado no registro de Joana:

[...] encerro este trabalho final com o prazer de ter feito parte deste espaço, com a sensação de dever cumprido e com muitos aspectos da minha formação mais consolidados e com a minha identidade profissional mais clara para mim mesma. (JOANA).

A APNP mostrou-se um lugar de respeito à diversidade de ideias e construção coletiva do conhecimento ao promover momentos de fala e de partilha, de integração da teoria com a prática, bem como da razão com a emoção, no qual a rigorosidade e a afetividade se fizeram constantes instigando a transformação dos modos de ser e estar professor/a.

\section{CONSIDERAÇÕES FINAIS}

Como professoras de EF compromissadas com a formação para a cidadania, não poderíamos nos eximir de pensar a discussão da EF e do esporte, apartada do contexto pandêmico atual, especialmente no momento, que é parte de um movimento que está em curso há anos, no qual a qualidade da Educação brasileira está ameaçada e, como bem salientou Martins (2020), evidencia o fracasso da Educação bancária sinalizada por Freire (1996; 2011b), a qual tem regido os variados processos de ensino e de aprendizagem das inúmeras IE do Brasil.

A APNP mostrou-se, dessa forma, como um significativo espaço de tomada de consciência acerca do papel social do/a professor/a de EF para a formação humana e para a transformação social. Ademais, alcançou um dos seus objetivos, qual seja, instigar os/as estudantes-professores/as 
do curso de especialização à reflexão acerca de sua prática pedagógica, a partir dos temas que permearam as discussões.

Hoje entendemos que a APNP permitiu alastrar o incêndio, pois outras fagulhas somaram-se às nossas, formando um fogaréu lindo. Fogaréu da transformação, da igualdade, da partilha, do afeto e do estudo. Fogo que nos move a fazer da Educação de forma geral e da EF, em especial, uma das vias para a promoção da formação humana e para a superação de todas as formas de opressão. Fogo do amor à profissão que escolhemos e pela qual juramos honrá-la com respeito e dignidade. Mas não é um amor qualquer, é um amor que "[...] seja, na verdade um 'amor armado', um amor brigão de quem se afirma no direito ou no dever de ter o direito de lutar, de denunciar, de anunciar" (FREIRE, 2021, p. 124).

Salientamos, que o exercício da escrita, no caso dos/as estudantes-professores/as da Especialização em Esporte Escolar a escrita das memórias e textos reflexivos, até pode parecer uma coisa trabalhosa, cansativa. Porém a escrita é uma das formas de "se armar", "armar de conhecimento" e fortalecer nossas compreensões. A escrita possibilita que a gente amadureça e se fortaleça para enfrentar as adversidades.

Por fim, inspiradas na canção de Toquinho e Vinícius de Moraes - Aquarela, a qual diz que "[n] essa estrada não nos cabe conhecer ou ver o que virá", pois "[o] fim dela ninguém sabe bem ao certo onde vai dar" e com aporte em Freire (1996, p. 85), que "[o] mundo não é. O mundo está sendo", reiteramos a convicção de que as mudanças são possíveis.

Desse modo, apesar da incerteza do futuro, entendemos que o aprendizado construído na APNP Estudos Avançados em Educação nos fez perceber que podemos recolorir essa linda passarela, promovendo a Educação problematizadora idealizada por Freire. Para tanto, convidamos a todos/as a seguir na caminhada pela construção de uma Educação pública, gratuita, de qualidade, problematizadora e emancipatória para todos/as.

\section{REFERÊNCIAS}

ANDRADE, Danielle Müller de. Cúpula Geodésica: um lugar potencializador da Educação EstéticoAmbiental. Orientadora: Elizabeth Schmidt Brandão. 2021. 180 p. Tese (Doutorado em Educação Ambiental). Universidade Federal do Rio Grande, Rio Grande, RS. 2021.

ANDRADE, Danielle Müller de; SCHMIDT, Elizabeth Brandão; MONTIEL, Fabiana Celente; ZITZKE, Viviane Aquino. Atividades remotas em tempos de pandemia da COVID-19: possíveis legados à Educação. Revista de Estudos e Pesquisas sobre Ensino Tecnológico (EDUCITEC), Manaus, v. 6, e150120, 2020.

FREIRE, Paulo. Pedagogia da autonomia. São Paulo: Paz e Terra, 1996.

FREIRE, Paulo. Professora sim, tia não: cartas a quem ousa ensinar. 31. São Paulo/Rio de Janeiro: Paz e Terra, 2021.

FREIRE, Paulo. Educação e mudança. 34. ed. São Paulo: Paz e Terra, 2011a.

FREIRE, Paulo. Pedagogia do oprimido. 50. ed. Rio de Janeiro: Paz e Terra, $2011 \mathrm{~b}$.

FREIRE, Paulo. Pedagogia da esperança. 23. ed. São Paulo/Rio de Janeiro: Paz e Terra, 2016.

FRIGOTTO, Gaudêncio. Pensando a Educação no Brasil com Gaudêncio Frigotto. YouTube, 20 ago. 2020. Disponível em https://www.youtube.com/watch?v=1iMbeJ9VSik\&t=7s. Acesso em 03 set. 2020. 
GIL, Antônio Carlos. Métodos e técnicas de pesquisa social. 6. ed. São Paulo: Atlas, 2008.

IFSUL. Instituto Federal de Educação, Ciência e Tecnologia Sul-rio-grandense. Projeto Pedagógico Institucional. 2015. Disponível em http://www.ifsul.edu.br/projeto-pedagogico-istitucional. Acesso em 31 mar. 2021.

IFSUL. Instituto Federal de Educação, Ciência e Tecnologia Sul-rio-grandense. Diretrizes para o desenvolvimento de atividades pedagógicas não presenciais no IFSul adotadas em rãão da pandemia (COVID19). 20 ago. 2020. Disponível em http://www.ifsul.edu.br/ultimas-noticias/3349-ifsul-aprovadiretrizes-para-o-desenvolvimento-de-atividades-pedagogicas-nao-presenciais. Acesso em 19 jan. 2021.

MARTINS, Raphaell Moreira. A trajetória da COVID-19 na Educação Física Escolar. YouTube, 14 out. 2020.2 Disponível em https://www.youtube.com/watch?v=rSPKIoBu1QM\&feature=youtu.be. Acesso em 14 out. 2020.

MENDES, Valdelaine da Rosa; SINOTI, Débora Avendano de Vasconcellos; BORBA, Jônatas da Costa Brasil de. Educação Física Escolar na pandemia da COVID-19: trabalho docente, currículo e aprendizagens. YouTube, 11 dez. 2020. Disponível em https://www.youtube.com/watch?v=9KVZT9Ykm8\&t=467s. Acesso em 31 mar. 2021.

MINISTÉRIO DA SAÚDE. O que é COVID-19. Disponível em https://coronavirus.saude.gov.br/sobre-a-doenca\#o-que-e-covid. Acesso em 24 fev. 2021.

MORAES, Roque; GALIAZZI, Maria do Carmo. Análise Textual Discursiva. 2. ed. Ijuí: Ed. Unijuí, 2011.

SANTOS, Boaventura de Sousa. A cruel pedagogia do virus. Coimbra: Edições Almedina, 2020a.

SANTOS, Boaventura de Sousa. A cruel pedagogia do vírus. YouTube, 25 ago. 2020. Disponível em https://www.youtube.com/watch?v=tJH5aYTqbSE\&feature=youtu.be\&fbclid=IwAR2BMrZ3 OsdmfFFMEYJ8ZdIMq40vMV1i9 R-kklbPT0LskvQ3770S14Lktc. Acesso em 03 set. 2020b.

SILVA, Maria Eleni Henrique da; MARTINS, Raphaell Moreira. Reflexos da pandemia na Educação Física escolar: uma reflexão possível à luz de Paulo Freire. In: SILVA, Maria Eleni Henrique da; MARTINS, Raphaell Moreira (org.). Pressupostos freireanos na Educação Física escolar ação e movimentos para a transformação. Curitiba: CRV, 2020. p. 25-48.

TAFFAREL, Celi. Educação Física Escolar e sociedade: abordagem crítico-superadora através do tempo. YouTube, 14 ago. 2020. Disponível em https://www.youtube.com/watch?v=jlmYK2OoDSg. Acesso em 03 set. 2020. 


\section{Informações das autoras}

Danielle Müller de Andrade

Instituto Federal de Educação, Ciência e Tecnologia Sul-rio-grandense

E-mail: danielleandrade@ifsul.edu.br

ORCID: https://orcid.org/0000-0002-4952-7570

Link Lattes: http://lattes.cnpq.br/4516190033005586

Fabiana Celente Montiel

Instituto Federal de Educação, Ciência e Tecnologia Sul-rio-grandense

E-mail: fabianamontiel@ifsul.edu.br

ORCID: http:// orcid.org/0000-0002-9921-6703

Link Lattes: http://lattes.cnpq.br/7208001902484898

Márcia Rejane Vieira Guimarães

Instituto Federal de Educação, Ciência e Tecnologia Sul-rio-grandense

E-mail: marciaguimaraes@ifsul.edu.br

ORCID: https://orcid.org/0000-0001-9121-0414

Link Lattes: http://lattes.cnpq.br/4208966023890524 